\title{
SUPPORTED EDUCATION \\ AS AN EMPOWERMENT \\ INTERVENTION FOR PEOPLE WITH MENTAL ILLNESS
}

\section{Chyrell D. Bellamy and Carol T. Mowbray}

University of Michigan

School of Social Work

\begin{abstract}
Many adults with severe mental illnesses experienced disability onset in early adulthood, causing interruption or indefinite postponement of postsecondary education. Supported education programs are a recent innovation to assist in integrating people with mental illness, who desire to resume their postsecondary education in an educational setting where they can experience life as a student rather than as a mental patient. This study reports analyses of focus groups conducted to assess the impact of a supported education program from the perspectives of students who graduated from the program. Themes emerged from the data and were grouped under the following headings: problems and concerns, wants and desires, impact of supported education, personal empowerment, collective empowerment, and postprogram supports needed. While the program did not primarily view itself as an empowerment intervention, results revealed that empowerment did occur and contributed to the intervention's emphasis on self-awareness, group support, and advocacy. (C) 1998 John Wiley E Sons, Inc.
\end{abstract}

Chyrell D. Bellamy, doctoral student, Joint Program in Social Work and Social Psychology, The University of Michigan, Ann Arbor. Carol T. Mowbray, Associate Professor and Associate Dean for Research at the School of Social Work, The University of Michigan, Ann Arbor.

This study was funded by the Community Support Branch of the Center for Mental Health Services, SAMHSA, through a grant to the Michigan Department of Mental Health (Grant \# HD5SM47669). It represents a collaboration between Schools of Social Work at the University of Michigan, Eastern Michigan University, and Wayne State University, and the Detroit-Wayne County Community Mental Health Board.

We would like to acknowledge the assistance of Peggy Frankie, the late Phyllis Levine and the MSEP staff for their assistance with the focus groups. A special thanks to all of the students from MSEP who participated in the focus group sessions.

Correspondence concerning this article should be addressed to Chyrell Bellamy, School of Social Work, University of Michigan, 1080 S. University, Ann Arbor, Michigan 48109-1106. E-mail: cbellamy@umich.edu 
Education ... becomes the practice of freedom, the means by which men and women deal critically and creatively with reality and discover how to participate in the transformation of their world (Shaull, 1995, p. 15).

According to the National Institute of Mental Health (NIMH, 1996), long-term, persistent mental illnesses (e.g., bipolar disorders, major depressions, and schizophrenia) affect some five million American adults. Community mental health services are often responsible for assisting people with psychiatric disabilities as they make the transition from medical and rehabilitation settings to the community (Renz-Beaulaurier, 1994). Worldwide, there has been a shift in services which simply place individuals with mental illness in existing programs to services that are developed to respond to the needs of consumers (Manoel-Bertolote, 1993). In the late 1980s, the World Health Organizations's (WHO) Mental Health Program launched an initiative of support which sought to reduce the disabling effects of chronic mental illness by highlighting the social and environmental barriers that in many cases, hinder treatment and rehabilitation (ManuelBertolote, 1993).

Education is a valued entity in this society, allowing many not only an opportunity to learn, but also to enjoy the benefits related to it, such as employment and status. Davidson and Strauss (1992) state that for those with psychiatric disabilities, "a heightened sense of self-efficacy in one area may engender efforts to be effective in other areas, such as social relations or symptom management" (p. 142). If community mental health professionals are moving toward innovative avenues by which the consumers can become empowered, self-determined individuals, supportive educational opportunities could be viewed as rehabilitative interventions. A structured program providing education opportunities with supports can serve as a model for how people with psychiatric disabilities can receive individualized and normalized rehabilitation toward personal goals. The purpose of this article is to examine the issues, needs, and problems of people with mental illness involved in a supported education program, based on findings from focus group analyses. The analyses revealed ways in which supported education assists in the empowerment process.

\section{LITERATURE REVIEW}

\section{Supported Education}

It is estimated that 25 to $50 \%$ of individuals with severe mental illnesses have some college experience (Tessler \& Goldman, 1982). Indeed, because of the onset of mental illness often occurs in early adult years, many prospective or current college students have had their postsecondary education interrupted or indefinitely postponed (Kessler, Foster, Saunders, \& Stang, 1995). In fact, people with psychiatric disabilities are often denied participation in education because of misconceptions regarding mental illness (Unger, 1994). Because of the stigma associated with psychiatric disabilities, formal education has neither been utilized as a source for rehabilitation outcomes nor as a way of promoting community integration (Unger, 1993).

Supported education has its roots in the Community Support Program of NIMH, which emphasizes client-driven services and programs (Egnew, 1993). Recognizing the need to establish meaningful programs for adults with mental illnesses, Boston University's Center for Psychiatric Rehabilitation initiated a five year (1983-1988) demonstration project called the Continuing Education Project (CEP) (Unger, 1993). The con- 
cept of supported education grew out of various career development programs in postsecondary settings similar to the CEP, and is similar to the definition of supported employment from the Rehabilitation Act Amendments of 1986: "Education in integrated settings for people with psychiatric disabilities for whom postsecondary education has not traditionally occurred or for whom postsecondary education has been interrupted or intermittent as a result of a severe psychiatric disability and who, because of their disability, need ongoing support services to be successful in the education environment" (Unger, 1993, p. 12).

Supported education services assist in integrating people with mental illness into an educational setting where they can experience life as a student. The programs are designed to take place at postsecondary institutions. The state of Massachusetts now has a total of five supported education programs, including the first program which began at Boston University. A Chicago-based psychosocial rehabilitation agency, Thresholds, also operates a supported education program for its members and other referred from outside agencies, named the Community Scholars Program. In several California Community Colleges, the Office of Disabled Student Programs and Services offers services specifically developed for students with psychological disabilities (Parten, 1991). Supported education projects continue to develop throughout the country.

\section{Program Description}

In recognition of the need to assist consumers to resume educational endeavors, the Michigan Supported Education Program (MSEP) was developed in metropolitan Detroit. The project was federally funded for three years, as a research-demonstration, and involved public-academic collaboration between state and local mental health agencies and four academic institutions. Presently, it is supported by the Detroit/Wayne County Community Mental Health Board. The purpose of the research demonstration was to test out innovative ways of providing supports and assistance to individuals with psychiatric disabilities who wish to pursue postsecondary education.

In its research-demonstration phase, MSEP enrolled 397 individuals in four cohorts. Participants were primarily recruited from case management and outpatient mental health settings. However, there were also some who were recruited from self-help programs, and by word of mouth. All participants met the following eligibility criteria for participation: (1) psychiatric disability for at least one year; (2) high school diploma or General Education Degree (GED) completed, or near completion; (3) interest in pursuing postsecondary education; and (4) consumers in the public mental health system or willing to accept services if needed during participation in MSEP. Fifty-two percent of participants were women and $48 \%$ men. The average age was 37 with a range of ages between 18 and 75. The average onset of psychiatric disability for participants was at age 22. African Americans made up $60 \%$; $39 \%$ were White, and $1 \%$ were of other race or ethnicity. Eighty-four percent received SSDI and/or SSI entitlements. Data collected from Management Information System (MIS) files on the psychiatric diagnosis of the participants indicated the $67.9 \%$ were diagnosed with schizophrenia, $10.4 \%$ depression, $14.2 \%$ bipolar disorder, $2.9 \%$ anxiety disorder, and $4.6 \%$ other. Forty percent of the participants evidenced problems in symptoms, social adjustment, and/or substance abuse. Thirty-three percent had attended college, but did not receive a degree. All previously considered educational opportunities out of their reach (See Mowbray, Bybee, \& Shriner, 1996, for further description of participants.) 
Supported education services include sessions on career planning and vocational assessments, assistance in obtaining financial aid, self-awareness, stress management, time management, rights and resources of people with disabilities, academic skill practice and development, and other support services. Michigan Supported Education Program services are provided through three models: structured classroom, group support, and individualized support all of which meet at Wayne County Community College. The structured classroom model utilizes a formal curriculum in a classroom setting, with a teacher and a teacher's assistant. Students meet twice a week for 2.5-hour sessions. The group support model meets the same amount of time, but operates more as a mutual support group. Meetings are less formal and content is based on the results of the group's internal needs assessment, where the group determines their agenda. Staff include cofacilitators, one of whom has self-identified as a consumer of mental health services. In the individualized model (quasicontrol) each student is assigned a staff contact person; however, the student arranges the meetings on an as-needed basis and on topics determined by him or her. For the active (group or classroom) models, 64\% participated to some extent, dropout rates were similar to other volunteer interventions (Bond, Drake, Mueser, \& Becker, 1997; Fortney, Blow, Bunn, \& Loveland-Cook, 1995; Luke, Roberts, \& Rappaport, 1993).

Results of quantitative analyses of graduation data, indicate the success of the program. The high enrollment indicates that people with psychiatric disabilities are interested in education and recognize its role in their goals of career development and recovery. After the six month follow-up time point, those with greater participation showed greater quality of life, empowerment, school/vocational enrollment, and encouragement from mental health workers. Better outcomes were found for the active models than for the individual (quasicontrol) condition. Based on data collected at program completion, a one-way ANCOVA found a significant condition effect for Empowerment $(F=4.96[2,209] p<.01)$ and for School Efficacy $(F=4.31[2,209] p<.05)$. The adjusted means were higher for classroom, followed by the group and then the individual condition. (See Collins, Bybee, \& Mowbray, 1996, for complete report of the quantitative results.) At 12-month follow-up, college or vocational enrollment increased significantly: form $7 \%$ to $21 \%$ for the classroom model and from $6 \%$ to $28 \%$ for the group condition (exact permutation McNemar Chi-Square Test, $p<.001$, respectively).

\section{CURRENT STUDY}

The present study was designed to provide a qualitative assessment of MSEP from the student's point of view. The inclusion of consumers in mental health services research clarifies "the important discrepancies between perceptions of consumers and professionals" (Campbell, 1996, p. 73). According to Campbell (1996), the "integration of personal experiences of illness, service, and treatment with professional knowledge recognizes the importance of each person's needs, expectations, and experience. ..." (p. 73).

\section{METHOD}

\section{Study Population and Procedures}

Two focus group sessions were conducted with students who graduated from the program. A convenience sample of approximately forty graduates of MSEP, representative 
of the research models, cohorts, and ethnic backgrounds, was mailed a request for their participation in a focus group to discuss their involvement in supported education. Questions were sent out in advance to give the students an idea of the format. Questions included: How did you first hear about MSEP and why did you decide to participate?; Discuss some of the reasons you are interested in getting more education; What is the hardest thing about being a part of MSEP or going back to school?; How did your casemanager or other professional people feel about you going back to college?; How should support happen when you leave MSEP? What would you like to have happen after graduation from MSEP in terms of support from MSEP? Two dates were arranged in advance to give participants choices to fit their schedules. However, out of approximately forty graduates that were telephoned, many indicated that they were unable to participate due to scheduling conflicts. Consequently, there were nine participants in the first group and seven in the second. Both focus groups were facilitated by the second author and averaged two hours. At the beginning of the focus groups, participants were informed that the sessions would be tape recorded and were made aware of the person in the room who would take field notes.

The demographics of these participants were representative of the larger sample. Twelve were African American and four were White. Ages ranged from 32 to 51 . There were eight women and eight men. The participants came from all three program models: four participants had been in the classroom; seven participants had been in the group model; and five participants had been in the individual model.

\section{Research Framework}

The qualitative interpretation of the focus group data involved inductive analysis, where the themes emerge from the data, rather than prior to data collection (Patton, 1990). This analysis complements the purpose of the focus groups: to record the individual and the collective voice of the participants within a supportive atmosphere, where people could share and learn from the experiences of each other.

Sessions were transcribed by the first author, based on field notes and tape recordings (Krueger, 1994). The analysis process involved an ethnographic approach, which relies more on direct quotations rather than using the content analysis approach, which produces numerical descriptions (Morgan, 1988). Both authors independently analyzed the transcripts and field notes to identify themes. The questions provided somewhat of a structure for thematic identification, and the analysis involved an iterative process of reexamination of the data and development of coding themes, until both authors agreed on a list of themes. This process is valued because it uses a multiple analytical process, which provides an opportunity to assess the utility of the major themes (Stewart \& Shamdasani, 1990). Unlike the larger sample, participant comments were not qualitatively different based on the condition they were assigned (classroom, group, or individual) in MSEP.

\section{RESULTS}

Themes were grouped under the following headings: problems and concerns, wants and desires, impact of supported education involvement, personal empowerment, collective empowerment, and supports needed after MSEP. 


\section{Problems and Concerns}

Focus group participants spoke of several problems and concerns which made it difficult for them to make the choice to return to school. Themes of stigma, prejudice, and fear were evident throughout the sessions. Stigma is felt at the individual level, within mental health systems, and other institutions, and in the larger community. It underlies many of the fears and self-doubts experienced by people with mental illness. As portrayed by these graduates of MSEP:

I always thought people would laugh. I thought the people in MSEP were mean at first. I thought people would stare at me. I was scared of the program. . . I didn't think that I could go through with it.

There were persons in our group who had negative responses from families. If you keep telling people that they are stupid or retarded that imprints on you mind. People with mental health illnesses are very sensitive to this. People say, "You ain't nothing, and you won't be nothing."

My biggest challenge was that I was prejudiced toward the project. I had judged the project before I even got in. We also stigmatize ourselves. I thought this was going to be another day hospital or adult nursery center. I was in a program like that before where we made napkin holders. I was in the shock of my life when I came into this project.

Some focus group participants also indicated that they often experienced negative attitudes from their social workers or psychologists; many stated that to them this translated into meaning that their therapists did not believe that they were capable of attaining their educational and career goals.

Financial concerns weighed heavily on the minds of the focus group participants. The majority of the group were people who had experienced a multiplicity of oppressions, as people of color, people with a mental illness, and people living in poverty-all adding to the increased feelings of marginalization they experienced. Many feared that to proceed toward their educational endeavors meant that their financial entitlements would be cut:

I have section 8 where I am living. If I go and get a full time job I am going to have to pay full rent. How do you adjust to it that quickly? If I was 18 years old and had a mom and dad, I could at least stay with them for a few months and adjust to it. But how can you do it that quickly? Plus I am on Medicine which they say I need to take for the rest of my life. What if you don't have the insurance? You can try and have faith and hope, but how can you make the adjustment?

I used to say it's okay if I can get food stamps and Medicaid at least. But now that I am not getting anything this month, I'm wondering, "What are we going to do? I have rent to pay, two kids ... how am I going to get them fed?"

I want to get off of SSI, but I am scared to get a job. I am scared to fail or to go backwards.

I could never understand Maslow-how can you get to the next level when you can't guarantee the first level? I'm afraid everyday that when I go home that there will be no more food stamps. 
While being a college student in the larger population is synonymous for most with having low income, for people already living in poverty, additional worries could cause postponement of postsecondary education indefinitely. Many also feared that worrying or stress would cause them to have a reoccurrence (relapse) of their mental illness. Some of their financial concerns were alleviated through collaborative efforts with other agencies; for instance, Michigan Rehabilitation Services provided financial and vocational resources for qualified students including tuition, books, and transportation assistance. However, a primary and legitimate concern was rooted in their daily struggle to meet basic needs such as adequate income, housing, food, and clothing.

\section{Wants and Desires}

Despite these obstacles, focus group participants clearly centered their desires to obtain education and/or employment. While many saw education as step toward reaching their career goals, they also saw it as a way to find meaning in their lives:

I saw MSEP as an opportunity for education. I felt like I wanted to change my life, give it some kind of meaning. I always wanted to go to school. I wanted to do something other than the jobs I had. The other jobs were just work to provide an income. So when MSEP came along, I said, "This is my chance . . . I need to go to school and concentrate on my education."

Education gives you a better chance to have an opportunity to do for yourself. With education, having a mental health disease, it instills greater confidence.

Participants wanted to be respected as people living in the community, not as patients with psychiatric disabilities—stabilized, but not independent or productive.

In regards to SSD, I was on it for ten years and I knew it would not last. I did not want it to last forever. I knew I would have to do something. I am sure that we all want to get to that point when we are cashing that paycheck.

\section{Impact of Supported Education and Involvement.}

While many participants were hesitant initially about supported education involvement, most were eventually positive about the program's benefits. Most obtained assistance to achieve goals they had long hoped for and many wanted to instill hope in others.

I signed up for MSEP sitting in the clinic. I saw forms sitting on the desk. I had problems since 1987 trying to get into Wayne County Community College. I had not given up hope of reaching my goals. MSEP gave support, encouragement, and knowledge to get into Wayne County Community College. So, I am looking forward to a new beginning in my life which I thought was a closed chapter.

MSEP was a hand up not a hand out. Something that instills confidence within self that we could do as well as or better than so-called normal people. It's as if we are ambassadors going to show so-called normal people we can function to their level or beyond. It has helped me to tear down stereotypes of mental health consumers-like with AIDS, people were scared because they did not know. Hopefully we can educate others as ambassadors. 
I always wanted to be a social worker. Once I became involved with MSEP, I wanted to do clinical work with mental health consumers specifically. Getting education about the mentally ill like myself and working with the public. I know I will get something.

My wife was very encouraged that I got out of the house, thought I was setting an example for my daughters. My mother really loved this program. When you have all these stigmas coming from outside, you get frustrated, thinking that you are not doing anything. When you're happy it radiates beyond you, and they pick up on that.

People living with mental illness at some point during the course of their disability have been disconnected from social existence. Several participants spoke about a sense of belonging which they experienced from group support through MSEP:

Just talking about everyday life with other participants and staff has increased my knowledge of myself and changed my perspective on a lot of biased (negative) attitudes I possessed and felt others possessed. The most beneficial thing about being involved in supported education, I definitely know, is the socialization.

In the group model I got a lot of emotional support-people would say, "You can do this, you have the capacity, you're intelligent, don't let the mental illness get in the way."

The group module we were in, I noticed the amount of confidence it gave all of us. Sharing our common goals. When it started out everyone voiced what they wanted to do-it was all about some sort of education or academics or trade or profession.... Then, everyone that has graduated they were going in some direction toward their particular goals.

I was so happy about MSEP that I cried. It provides unity. Now I feel that I am not alone. I don't feel isolated. I feel good about myself.

\section{Personal Empowerment}

Definitions of empowerment share some similar fundamental terms: sense of control, capacity building, collaborative partnership, increase in power, equity in resource allocation, critical consciousness, to name a few. Some theorists make a distinction between personal and collective empowerment. Personal empowerment "involves experiencing oneself as an effective and capable person" (Gutierrez \& Gillmore, 1995, p. 4). Collective or community empowerment is the process by which individuals come together and develop an awareness or "group consciousness" about the impact of societal structures and how they impact on the group (Gutierrez, 1995). We focus first on personal empowerment.

People with mental illness can become empowered through the process of gaining control of their lives (Zimmerman, 1995). Ways in which supported education promoted this process include: assisting students to develop coping and stress management skills, involving students in their own decision making, as well as in the programmatic development of supported education, and educating students on the rights of people with mental illness. Focus group participants spoke of ways which they felt being involved with MSEP gave them a sense of having "real" power and/or control: 
By being in the project it helped me to reach out and to let people know that I was having problems. It taught me to step up and let these folks know what you needed. I took advantage of some of the programs involved in the school like special populations. And it also gave me what I need to go in and tell the instructors that I'm in special populations and have this kind of problem or that kind of problem and I may need you to give me extra help or to help me with this.

MSEP gives you a sense of empowerment. They told you that you were capable of doing. It gave you a sense that you can help solve your problems, not that all problems were solved. But that you did not have to be a victim, but that you did have power and that you were capable of working through difficulties you face.

\section{Collective Empowerment}

Several participants also expressed a sense of collective empowerment through involvement with supported education. An effective empowerment strategy is developing power with others to effect change (Wallerstein, 1992). Supported education promoted collective empowerment by providing a mutual help-group atmosphere and by involving students in the programmatic development of MSEP. Many spoke of the rights of people who are mentally disabled and wanted to organize around those efforts:

Recently, I heard about the physically disabled marching to the State Capitol. We should do some activism, bring about a political awakening regarding mental health discrimination. There is strength in numbers. When you have a mental illness it becomes an individual thing and you need support from others. We should join in and march. We need to let them know that we are registered voters.

We need to go out and get other people involved. It would be good for them to hear from students. It helps a person to talk with people who have walked in their shoes. We need to go out and take former students into mental health centers. That might help to bring more people into the program to see how we have benefited... .

I spread the word. I am extremely positive about MSEP. Anyone who has mental and emotional problems can only get better.

This feeling of collective empowerment moves toward an advocacy process. Like Freire (1995), many advocates see awareness being brought about by education and increases in knowledge (knowledge $=$ power). The focus group participants also commented on the advocacy efforts of supported education staff members, who provided support and assistance:

I have been involved with MSEP since May '93. It has been enriching for me because they stuck with me through hospitalizations. They came out to visit while I was in the hospital and they gave me encouragement to continue. I will be back in school. This has been powerful. It's a positive situation and I am happy to be affiliated with MSEP.

Staff roles in supported education resemble more those of advocates than rehabilitation or treatment providers; that is, according to Freddolino and Moxley (1992), advocates 
are persons who represent consumers and their wishes, based on the consumer's expression and definition of those wishes.

\section{Supports Needed After MSEP}

Supported education was designed to be a time-limited intervention, facilitating educational institutions, with community mental health or vocational rehabilitation programs eventually taking over support and advocacy for consumers' vocational and educational needs. While participants report that supported education had an important impact on their lives, they also expressed a desire for continued affiliation with staff and peers from the MSEP program. Initially, MSEP attempted to start mutual support groups for students attending college, but this did not work out. Participants discussed the difficulties they experienced after graduation from MSEP because they needed additional supports in place:

I had little support when I was no longer in class ... I felt like you were all just putting the program together. Although I did see people on campus I knew from MSEP, I was pretty much alone. Everyone lived so far away from campus.

Since we were on a commuter campus, we were all scattered. It's hard to get people together at one time. I felt like I did not want to bother the MSEP project because there was a new cohort.

At the end of the focus group session, participants generated a list of suggestions for follow-up services to be considered for implementation, including an alumni association, more postgraduate meetings, a student managed a hotline to assist other students who are having difficulties, and a resource guide of supportive services for persons with mental illness. More education and advocacy may be needed with community mental health, vocational rehabilitation programs, and college special student service programs to develop or strengthen educational and vocational support services for students.

\section{DISCUSSION}

Participant responses from the focus groups showed the many benefits of supported education, ranging from concrete assistance to support services, to personal and collective empowerment-all geared toward assisting people with mental illness to attain their educational goals. Specifically, opportunities were available for: academic skill development, career planning and assistance in applying to college; providing a mutual support environment with staff advocacy and support; involvement in decision making (personal and group); and learning about the rights of people with mental illness. The themes which emerged from the data are consistent with processes of change reflected in empowerment (Gutierrez, 1994). Gutierrez (1994) conceptualizes the elements of change as consisting of the following four subprocesses: a) increasing self efficacy; b) developing a critical consciousness; c) developing skills; and d) involvement with similar others. It is clear, that while empowerment was not initially a major focus of the supported education program, based on the comments of the focus group participants, it was an important aspect of their rehabilitation and integration in both the educational community and the community at large.

Empowerment can also have mixed benefits. Consumers have to acknowledge, as well as take responsibility for, the results of the empowerment process, which may not 
necessarily lead to desired outcomes (Freddolino \& Moxley, 1992). For example, students reported the disappointment they experienced because of the negative reinforcements from professionals, when they tried to advocate on their own behalf. Community practitioners play a key role in the lives of consumers. Out of fear that their clients will experience a mental illness "relapse," some discourage participation in educational pursuits. While perhaps well-intended, such paternalistic attitudes are still stigmatizing. Link, Cullen, Struening, and Shrout (1989) suggest that stigma itself can leave consumers vulnerable, making them more likely to experience a relapse of their disorder. Psychiatric illness, even if serious enough to require hospitalization, does not preclude continued education. Unger (1994) reports two supported education sites in which participants returned to their supported education program after hospitalization. Several focus group participants also reported returning to supported education upon discharge from inpatient treatment.

Finally, supported education programs, while empowering, are not enough. Focus group participants clearly identified the need for additional supports to be in place after graduation form MSEP. Community support programs must work more effectively with community psychologists, social workers, and with faculty and staff of educational institutions to more effectively integrate participants into the community at large. To move toward community integration, a process by which "all people, regardless of any differences, belong in a community" (Carling, 1995, p. 15), all in society must work at eradicating negative attitudes and judgments towards people with mental illness.

From an empowerment perspective, by sharing and listening to each others' experiences, the participants themselves create a community narrative, "a story that is common among people" (Rappaport, 1995, p. 803). A new community narrative is often formed in mutual help organizations because "people provide social and emotional support, and offer one another new ways to think and talk about themselves" (Rappaport, 1995 , p. 804). Documenting the experiences and voices of those living with and surviving mental illness is one step in dispelling stigma. If community integration is the goal, we must ensure that those living with mental illness have supports for educational and work opportunities. Community psychologists have demonstrated that empowerment strategies are effective with disenfranchised and stigmatized populations. However, there are not many programs structured along these lines for people with psychiatric disabilities. These focus group results suggest that a supported education approach can prove to be effective in empowering this population.

The limitations of this study should be acknowledge. The number of participants was limited and may not necessarily be representative of the entire group if MSEP participants, although these qualitative results were certainly congruent with the empirical findings, based on the entire group. Also, it should be kept in mind that MSEP served a primarily urban population and findings may not generalize to other geographical areas. Nonetheless, we believe that the focus group results provide a more complete description of the empowerment process and possibilities in adults with psychiatric disabilities.

\section{REFERENCES}

Bond, G. R., Drake, R. E., Mueser, K. T., \& Begker, D. R. (1997). An update on supported employment for people with severe mental illness. Psychiatric Services, 48 (3), 335-346.

Campbell, J. (1996). Towards collaborative mental health outcomes systems. In D. S. Steinwachs, L. M. Flynn, G. S. Norquist, \& E. A. Skinner (Eds.) Using client outcome information to improve men- 
tal health and substance abuse treatment. New Directions for Mental Health Services Series (No. 71, pp. 69-78) San Francisco: Jossey-Bass.

CARLING, P. J. (1995). Return to community: Building support systems for people with psychiatric disabilities. New York: The Guilford Press.

Collins, M., Bybee, D., \& Mowbray, C. T. (1996). Effectiveness of supported education for individuals with psychiatric disabilities: Results from an experimental study. Unpublished manuscript, University of Michigan, Ann Arbor.

Davidson, L., \& Strauss, J. S. (1992). Sense of self in recovery from severe mental illness. British Journal of Medical Psychology, 65, 131-145.

Egnew, R. C. (1993). Supported education and employment: An integrated approach. Psychosocial Rehabilitation Journal, 17 (1), 121-127.

Fortney, J. C., Blow, F. C., Bunn, J, Y., \& Loveland-Cook, C. A. (1995). The effects of travel barriers and age on the utilization of alcoholism treatment aftercare. American Journal of Drug Alcohol Abuse, 21 (3), 391-406.

Freddolino, P. P., \& Moxley, D. P. (1992). Refining an advocacy model for homeless people coping with psychiatric disabilities. community Mental Health Journal, 28 (4), 337-351.

Freire, P. (1995). Pedagogy of the Oppressed 20th Anniversary (Ed.). New York: Continuum Press.

Gutierrez, L., (1995). Understanding the empowerment process: Does consciousness make a difference? Social Work Research, 19 (4), 229-237.

Gutierrez, L., \& Gillmore, M. R. (1995, May). Women and empowerment: Issues for health education and promotion. Paper presented at the meeting of the Midwestern Psychological Association, Chicago, IL.

Gutierrez, L. (1994). Beyond coping: An empowerment perspective on stressful life events. Journal of Sociology and Social Welfare, 21, 201-219.

Kessler, R. C., Foster, C. L., Saunders, W. B., \& Stang, P. E. (1995). Social consequences of psychiatric disorders: Educational attainment. American Journal of Psychiatry, 152 (7), 1026-1032.

Krueger, R. A. (1994). Focus groups: a practical guide for applied research. Thousand Oaks, CA: SGE.

Link, B. G., Cullen, F. T., Struening, E., \& Shrout (1989). A modified labeling approach to mental disorders: An empirical assessment. American Sociological Review, 54, 400-423.

Luke, D. A., Roberts, L. \& RAppaport, J. (1993). Individual, group context, and individual-group fit predictors of self-help group attendance. The Journal of Applied Behavioral Sciences, 29 (2), 216-238.

Manuel-Bertolote, J. (1993). WHO in action: Empowering the mental patient. World Health, 46 (2), 28-29.

Morgan, D. L. (1988). Focus groups as qualitative research. (Sage University Paper, Qualitative Research Methods series, Vol. 16). Thousand Oaks, CA: Sage.

Mowbray, C. T., Bybee, D., \& Shriner, W. (1996). Supported education for adults with psychiatric disabilities: Characteristics of participants. Psychiatric Services, 47 (12), 1371-1377.

NIMH. (1996). Mental illness in America: The National Institute of Mental Health agenda [On-line]. Available: World Wide Web: http:/ /www.nimh.nih.gov/about/america.htm.

Parten, D. (1991). Resource guide for serving students with psychological disabilities in California community colleges. Sacramento, CA: California Community colleges' Chancellor's Office.

Patton, M. Q. (1990). Qualitative evaluation and research methods (2nd ed.). Thousand Oaks, CA: Sage.

RAPPAPORT, J. (1995). Empowerment meets narrative: Listening to stories and creating settings. American Journal of Community Psychology, 23 (5), 795-807.

Renz-Beaulaurier, R. (1994). The role of choice in empowering people with disabilities: Reconceptualizing the role of social work practice in health and rehabilitation settings. In L. Gutier- 
rez, \& P. Nurius, (Eds.), Education and research for empowerment practice (pp. 195-205). Seattle, WA: Center for Policy and Practice Research.

Shaull, R. (1995). Forward. In P. Freire (Ed.), Pedagogy of the oppressed (20th anniversary ed., pp. 11-16). New York: Continuum Press.

Stewart, D. W., \& Shamdasani, P. N. (1990). Focus groups: Theory and practice. (Applied Social Research Methods Series, Vol. 20). Thousand Oaks, CA: Sage.

Tessler, R. C. \& Goldman, H. H. (1982). The chronically mentally ill: Assessing community support programs. Cambridge, MA: Ballinger.

Unger, K. V. (1994). Access to educational programs and its effect on employability. Psychosocial Rehabilitation Journal, 17(3), 117-125.

UNGER, K. V. (1993). Creating supported education programs utilizing existing community resources. Psychosocial Rehabilitation Journal, 17(1), 11-23.

Wallerstein, N. (1992). Powerlessness, empowerment, and health: Implications for health promotion programs. American Journal of Health Promotion, 6(3), 197-205.

Zimmerman, M. (1995). Psychological empowerment: Issues and illustrations. American Journal of Community Psychology, 23(5), 581-599. 